\title{
DIGITAL PAYMENTS: INDIA GEARS UP THE DIGITAL FAST LANE BY INNOVATION ZIPPING
}

KEY WORDS: Digitalization, Artificial Intelligence,

Omnichannel, wow, video-basedinteractions

\section{Pallavi Pandey* Dr Bilal Mustafa Khan}

\section{Dr Harish Singla}

Research Scholar Aligarh Muslim University. *Corresponding Author

Associate Professor, Aligarh Muslim University.

\section{Sr. Associate Professor, National Institute of Construction Management \&} Research.

COVID-19 has brought the challenges to the business industry. This pandemic has forced the banking industry to adopt digitalization and new-age technologies. Due to the pandemic banks aim to deliver best-in-class customer service and frictionless experiences to their customers. COVID-19 has accelerated the need for digital solutions, video-based interactions and omnichannel experiences. These features of digital platform are necessary for banks to provide uninterrupted services, safely to customers and allow business as usual. Artificial Intelligence and Machine Learning are enthusiastically adopted by the industry to transform their decision-making processes and focus aggressively on costs. Customer experience is the primary focus for the banks that are looking for ways to improve it either with their applications or simplifying customer journeys and introducing omnichannel experience. COVID-19 has forced banks to focus on end-to-end digitalization that enable businesses to function, while "wow" (walk out working) factors such as dashboards take a back seat.

\section{INTRODUCTION}

Seamless payments for the most of the daily transactions are used by the customers. It is increasing the expectation for secure pay and integrated ways to products and services. For players in digital payment ecosystem means a set of real choices to consider. The Coronavirus pandemic, which severely damaged many sectors, has inadvertently helped India's digital payments market rapidly gaining in scale.

Daily users of digital payments have increased exponentially. Every day, more than 100 million customers use digital and electronics platform channels such as debit cards, Unified Payments Interface (UPI), ewallets, Fastag or Aadhaar Enabled Payments (AePS). While making transaction customer put their trust on an intricate network of companies and technology architecture seeking to make process 'invisible.

Digital Payment is attempting to displace the centuries old practice of handling over tangible currency to the nearby merchant in return for desired goods or services, and counting the change of fool proof the exercise.

"The future of digital payments is in making them natural and effortless and thereby invisible", said Navin Surya, founder of Fintech company Itzcash, who is now building a New Umbrella Entity (NUE) So Hum Bharat Along with CC Avenue and Yes Bank.

"There is an inherent risk in handling currency, which gives it a certain value. With technology enabling cash to go digital, these risk appetites could get personalised, and in India, the innovation could be in this direction," according to Surya who is also the Chairman Emeritus of the Payments Council of India.

India is a country of diverse culture and risk sensibilities; a complete digital economy may not be immediate reality.

Pandemic stricken in year of 2020 , saw the adoption of digital payment like never before and expects 2021 will be year of innovation. Consumers are adopting new technology from traditional banks to new age fintech companies, the digital payments in the country are enabled by a network of companies that see payments innovation as an endeavour to not just create convenient solutions. It is also driving mass adoption among consumers through sustainable business models. The ecosystem of India's FinTech is accelerating a unique growth path as it rides on digital public infrastructure and leans on partnership too. 200mn active customers are already scaled up through digital payment.

\section{Literature Review}

Though the digital payment was already established past few years and was taking upward trend but the national wide lockdown enforced in March 2020 enforced and accelerated the adoption of digital payments. Covid-19 led to a surge in the usage of digital payment modes among consumers; kirana stores also embraced this model easily. These factors together are likely to create a revenue pool of Rs 2,93,700 $\mathrm{Cr}$ by 2024-25 for payment players- a figure that stood at Rs 1,98,200 Cr in 2019-20. (PwC Indian Payments Handbook)

The ease of digital on- boarding and adoption of transaction technologies will pave the way for businesses to be built on top of payment platform such as UPI bringing in next 100 million users to digital payments (Harshil Mathur, Cofounder \& CEO, Razorpay, 2020). This showed in massive influx of registrations among small businesses adopting digital channels, the transaction volumes have increased exponentially by $40-45 \%$ over the last few months during pandemic. In the year of 2020 which was full of unprecedented changes and challenges, it posed some interesting opportunities for businesses to embrace digital payments and many moved their business online for the first time, ushering in a new digital transformation.

\section{AWindow of Opportunity}

Digital Payments is showing growth in FinTech, with India's unique digital public infra and embedded offerings in partnership with incumbent financial players driving growth in other financial products. Even as adoption of digital channel in 2020 was first time for millions of customers, less than $25 \%$ of the banked population in the country, or about 200 million users, actively transact on any mode of digital channels. Similarly, merchant payment players have added VAS, consumer financing and merchant lending at POS to garner a higher wallet share.

This had made India a unique country in processing among the most volume of digital payments in the world after China, also lead the chart on being the most underpenetrated digital economies in the world. During pandemic use of local have become more vocal and people have started shedding use of 
traditional banking channels and caught in to using alternative digital channels.

Retail digital lending has delivered approximately $47 \%$ CAGR over the past seven years and has reached more than US $\$ 110$ bn in 2019. (Credit Suisse) This growth is led by the emergence of many specialised digital lenders like pay day, $\mathrm{SME}$, unsecured retail and BNPL lenders who are differentiated by fastest disbursements, many times within few minutes for small ticket consumer or personal loan, using alternative sources for underwriting and to reach out to customers. Retail digital lending has gained nearly more than $40 \%$ of the market share in personal loans and $20 \%$ in unsecured loans.

The primary target segment for a large section of digital lenders is to provide small ticket, contextual unsecured credit, as they lend to customers having no credit or limited credit record. The average ticket size for personal loans by FinTechs is $0.02 \mathrm{x}$ of average ticket size for banks and is $0.8 \mathrm{x}$ in case of durable consumer loan. (Experian, 2019). The average ticket size is increasing for digital lenders as addition of new loan products with higher ticket size and tenure based on confidence in their underwriting models. Lending to existing non- delinquent customers help in improving profitability, given better asset quality and otherwise high customer acquisition cost.

\section{On the Digital Highway: Pandemic Effect}

E-commerce players and FinTech have started offering small credit personal loan or small short-term credits to monetise their user base with banks or NBFCs. Many specialized digital consumer financiers have emerged to provide EMI, Buy Now Pay Later (BNPL) either at POS for offline or as a payment mode at the checkout page for online for 150mn customers. PayTm, Flipkart and Amazon provides short term credit for 15-30 days of 5-60k online transaction, it helps in increasing financing option when credit card penetration in India remains low at approx. $4 \%$. Some specialized players such as KrazyBee , LazyPay, Zest Money, Simpl provides transactional credit with longer tenure, high ticket loans to existing customers having good repayment behaviour too.
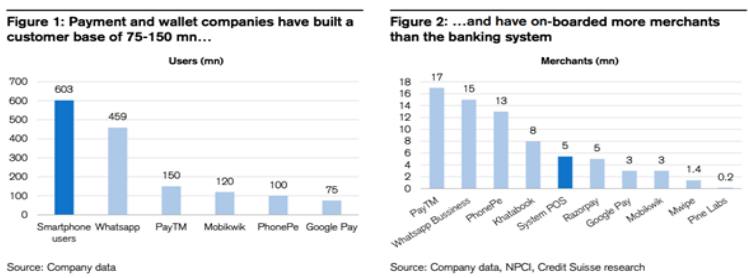

FinTech Brokers are rapidly expanding their retail broking market and have gained approximately $20 \%$ market by March 2020. Post the pandemic, within nine months growth for entire sector has accelerated with total broking accounts to 50\% nearby. Prominent leaders were Zerodha and Upstox with their users bases growing $100 \%$ and $160 \%$ respectively, to become largest retail brokers in India. Video eKYC and Aadhaar based authentication helped in accelerating digitalisation during pandemic. Thus, new age FinTech have accelerated market share gains and now covering $36 \%$ of total active brokers account in India. On the other hand, traditional brokers have also added customers but at slow pace which is reflected in the loss of market share.

\section{The India Stack}

India Stack is the platform to bring digital age by the trinity of higher banking penetration through Jan Dhan accounts, Aadhaar based unique identification and e-authentication and increased internet. These three together create public infrastructure which enables instantaneous, paperless and cost-effective customer authentication. Indian digital players have innovated on top position of digital infra within short period of time.

\section{India Stack}

Covid 19 has accelerated digitalisation globally across categories such as communication, shopping and payments etc. Segments like travel and entertainment would gradually recover as pandemic will slow down. As nation comes out of pandemic, there is widespread consensus that it has brought structural change in shopping and payments with the accelerated pace of digitalisation.

The critical pillars of economy are banking and payments, these are among the core areas that have been seen a major growth in digital offering and adoption. Going to be digital is not new to the economy only covid 19 has accelerated the pace of adoption of digitalisation. National Payment Council of India had launched innovative and successful initiatives like UPI, IMPS, Bharat Bill Payment and Electronic Toll Collection (ETC) through FasTag. Indian FinTechs and digital payments companies is showing significant progress and now these are offering user friendly solution and wide integrated solutions which will leverage advanced technology. Availability of low-cost data plan has increased the growth of usage of internet and mobile penetration and this also effect the shift from offline to online shopping channels.

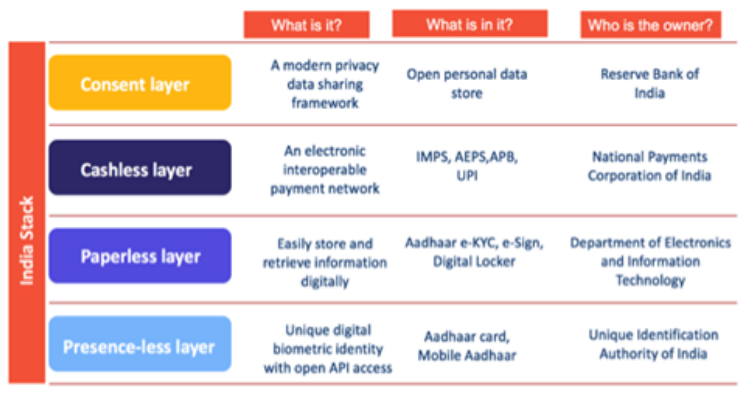

Source:Fintechfuture

\section{Digital Payments boost the customer experience to drive revenue}

Omnichannel marketing strategy for a 360- degree customerview

Customers expect seamless experience across industries. So, banking industry is no exception. Customers want embedded digital channels in their busy lifestyle, as with globalization and changing customer needs. Customer's seamless experience means making the corresponding customer journeys simpler, smoother and sustained. For this it implies that banks must achieve the highest levels of multichannel delivery outcomes and become truly omnichannel.

Banking industry is working on "omnichannel compatibility". It implies that customer should not experience any gaps as they move across the channels. A customer could be able to start journey in one channel, pause on it, move easily to another channel to be picked up later to complete the same journey. A customer should be able to choose products or services from any location and channel of his/her choice without any hassle and still have a consistent experience. Customers should be allowed to choose the most efficient and comfortable way for them to interact and still change their minds in mid-way.

Digital platforms help provide the centralized and synchronized orchestration of all customers through 360degree view of customers. Customer interactions across multiple touch points must be device agnostic. Digitalization bring omnichannel interactions and significant cost saving and it will be achieved by integrating channels, products, processes, peripheral applications and underlying data and infrastructures. Digital platform is changing the bank's focus from being "inward- centric" to being "customer- centric". For this, banks need to think first about all the possible 
interactions the customers might want to have before thinking about the channels, processes, devices, technology and applications and collaborate with third- party providers and fintechs in order to provide a better customer experience. For example, Poland' s Bank Millennium has implemented mass personalization based on customer behaviour segmentation. As a result, bank sold half of its retail loan through digital channels. Royal Bank of Canada has implemented an AI that provides easier, faster, more accessible and proactive services to its customers.

\section{Digital Onboarding of Customers}

Digital customer onboarding makes fast and seamless onboarding. Covid-19 pandemic, have forced banks to increase their investments in digital customer onboarding. Early adopters have got the benefits, as it ensured the continuity of business during the pandemic and operational and regulatory risks was very less too. Some of the Asian banks such as DBS, UOB, Axis Bank and ICICI Bank have already established customer onboarding processes efficiently.

Video based KYC is implemented to adhere local regulations. Indian Banking Regulator has also issued guidelines for video-based KYC. Spanish regulator SEPBLAC is in its digital onboarding process, where customers are allowed to show their ID proofs through a webcam or smartphone camera to complete KYC process.

During onboard, accurate capturing of customer data and digitalizing the data as its originating is important to make process effective. OCR (Optical Character Recognition) reads details from customer documents in real time and extracts the required data for onboarding. Connection with larger ecosystem by integrating with open APIs will help in seamless connect to third-party databases including credit bureaus and government databases and verify customer data and ensure they comply with regulatory laws in real time. Real time authentication will reduce the risk of frauds as any customer non-complaint with AML, FATCA, OFAC and PEP rules.

AI helps bank function in multiple way to enable quicker and secure customer onboarding. Image forensics and face match is performed by using AI very easily as it also enables analyzing customer data and ensuring all loopholes are plugged. It automates the analysis of multiple customer documents for sufficiency and accuracy to drive a binary decision for onboarding new customers. Time needed is reduced to complete the process from days to minutes. AI helps in strengthened the verification of signatures by crosschecking them with multiple ID proofs, further securing the agreement creation process. For example, RBS NatWest has enabled selfie based current account opening and other Global banks such as HSBC, Capital One, Wells Fargo and Barclay use biometrics and facial and voice analytics in digital onboarding of customers.

\section{Fintech collaboration for innovation}

Historically, banks were focused on "run the bank" activities and meeting mandatory regulatory changes, there were no budget or interest to adopt technology and innovation. Now a days delighting customers are priority, this also exemplifies the emergence of GAFA (Google, Apple, Facebook, Amazon) as real threat to the banking industry.

Covid-19 has accelerated the business environment today poses competition from many neo-banks and digital-only banks and forced banks to collaborate and fast-forward innovation. Collaboration with banks would help to be advance technologically and boost growth. Dealing with Fintechs and its innovation technologies would help in areas such as digital lending, analytics, default and credit risks and better customer insight to determine the development of future banking products. Fintechs innovation technologies stack is built on the efficient application of data science, AI, ML, blockchain and cloud.

Today there are many factors driving bank to rethink and partner with potential fintechs in their area of business. Banks need to shift quickly from their conventional mode of innovation to a partnership-based innovation as millennial customers demand seamless and real time experiences. Bank's execution will be speed up in digital transformation and meet customer expectation only when collaboration with fintechs. Some of the large banks have acquired the stake in these companies too. Royal Bank of Scotland has bought $25 \%$ stake in UK based fintech Loot which offers prepaid card solutions and current account. HSBC has collaborated with Australian fintech Identitii to help streamline client experiences and automate accounts aggregation. Barclays Bank has joined the force with fintech Bink in introducing an efficient loyalty program for its cardholders.

\section{Improvement in operational efficiencies and cost effectiveness through digitalization}

The economic impact of COVID-19 has been hurtful. Banks are searching different ways to optimize costs and improve efficiency. Since pandemic has impacted the economy and revenue of banking industry to unexpected hit so now banks have no option but to look at factors that can push the revenue level as high as possible. A robust technology framework can only help banks to enhance operational efficiency and fight against volatility or business stress. For this, a strategy for process optimization, digitalization and automation must be formulated.

RPA, OCR and blockchain are some technological drivers for banks to automate manual approaches and make their processes efficient. These technologies will help in reduce risk and enhance growth and each can make a difference and an amalgamation of technologies can result in drastic change. Earlier, banks have been ignoring the need of modernize the manual back office but now the back office has become the centre of innovation. Banks are maintaining multiple backoffice legacy systems, which operate in silos. Some of the banks are transforming their back office using automation.

OCR is the technology which is used to improve back-office operational efficiency, this helps with document verification, extracting data from documents, billing, customer onboarding, data origination and digital signature verification. OCR enables $24 * 7$ digital service.

Blockchain is a system which has enhanced visibility, increased efficiency and reduced operational costs and has allowed the creation of solutions for some of the challenging business functions such as collateral management, document management, cross-border payments, trade contract management among others.

RPA operates efficiently and make the best use of their resources. RPA is possible through integration with AI to create what is called intelligent RPA. For ages, banks have been ignoring the usage of RPA but now the banks have realized the need for RPA and proactively taking ownership of the transformation of operations through RPA-driven processes. Some of the prominent names in RPA market are Blue Prism, Automation Anywhere, UiPath, Workfusion, PegaSystem and Niche.

\section{Cloud for resilient and flexible infrastructure}

Customer expectations, emerging technologies and new business models are challenges faced by financial institutions and all these agenda items see regulatory compliance loom in the background. Cloud technology helps in facing these challenges and it changes banks' approach and logic in finding solutions to problem. Cloud is more elastic alternative to an on-premise data storage compute option and 
comparatively less expensive and faster. Cloud aids in connect the enterprise, since changes in consumer behaviour have led to core system upgrades, automation of back-officelinked processes and the elimination of data silos. Cloud collects, store and analyse data efficiency and it also helps in enterprise-wide synchronization by breaking operational and data silos, such as customer support, finance, risk and regulatory compliance across functions. This helps in solving customer issue by integration of business divisions, sharing data and driving combined decisions.

AI, ML, NLP, IoT and virtual reality are the new tools levered with cloud to create a strategy for customer experience, offers, optimizing operations and talent management as Cloud encourages business innovation. Some of the big data companies are using cloud and spending huge amount in digital transformation. Google Cloud has signed a deal with Lloyds Banking Group for 5 years for digital transformation projects to modernize customer experiences.

Cloud establishes application infrastructure that is secure, resilient and easily approachable when needed. These characteristics are used in dealing with worst business exigence such as COVID-19 pandemic.With the help of cloud infrastructure, banks' respond quicker to outages and disruptions through data backup and seamless recovery. Security on cloud is as secure as an on-premise environment. Goldman Sachs has started a rollout of a vertical cloud platform specifically to be used by financial institutions.

\section{Decision making made by $\mathrm{AI}$}

Banks across the globe are tending towards technology, since innovation has always been difficult for banks. Regulators are accepting the usage of technology and favouring the adoption of advanced technology such as AI, in areas which are human intelligence dependent. Digitalization and APIfication are base of AI-driven decision-making.AI models in decision-making rely on data to make real-time decisions. So, banks have to connect with external parties using APIs. Hong Kong Monetary Authority has adopted AI, automation and analytics by including revolutionary guidelines that will drive the banks under its jurisdiction towards nextgeneration banking through automated AI-driven systems. New AI model result in significant time saving as decisions will be made in real-time, especially in retail loans, auto financing and credit-cards.

\section{Recommendations}

Banks must deliver an interactive, personalized experience through multiple channels and enabled for multiple devices, through a digital banking platform. So, banks need to adopt an omnichannel strategy to retain their customers. The regulators of the banks are on-board and banks are increasingly wanted to address the limitations in legacy onboarding processes. Regulators are reacting positively and are approving the increased use of digitalization in customer onboarding also, but for this so bank should start thinking ahead too, as they need plan to introduce digital and customer using combination of technology through transformational programs. Developing a framework for digital application with an identified accreditation process built around digital customer will make them more competitive. Analysis of all the pros and cons and challenges and risk is also very important for the growth strategy of bank, so a lean team is needed to identify and analysis. This team should lay out a timeline and an approach regarding how the bank will transition into the identified banking-model. Choosing an appropriate model or combination of models is key strategy. AI can also aid in risk and portfolio management, as banks are moving towards digital platform and automated decision-making it is important to ascertain the threshold for risk tolerance and maximum risk bearing a bank would like to take. Many factors today are driving to rethink in their business area as banks need to evaluate "build vs. buy" at every stage of their technology investment. Bank was never open but for the seamless experience of customer, it must carefully determine the right- fit fintechs because building a customer base is no small feat. A mutual trust has to be built in order to drive the same objectives of making seamless experience of customers to make their lives easier and boost experience too. Cloud adoption will help banks to increase operational efficiency, scale up, create new business and aid in banks equip themselves with the capacity to be able to process massive, fluctuating volumes of data.

\section{CONCLUSION}

The Banking System is aligning business and technology with fresh talent and newer ways of working for new technology solutions with the latest skills sets for all the departments. Although branch numbers are shrinking but they will not go extinct. Financial institutions are implementing new business and operating models to increase revenue generation and operational efficiency too. Increased adoption of technology has enhanced automated manual tasks with a safeguard a bank against any pandemic-led lockdown. The biggest disadvantage is that presently banks are providing seamless customer experience but they do not have a full view of client's data outside their boundary, customers are using more than one bank for their savings and investments. Due to COVID-19, even though the business environment is tough, banking systems are taking appropriate steps to safeguard the interest of employees, shareholders and society at large.

\section{REFERENCES}

1. Adapa, S., Roy, S.K., (2017). Consumers' post-adoption behaviour towards Internet banking: empirical evidence from Australia. Behaviour \& Information Technology, 36(9), 970-983.

2. Ahuja G, Morris Lampert C (2001) Entrepreneurship in the large corporation: a longitudinal study of how established firms create breakthrough inventions. Strateg Manag J 22:521-543.

3. Auer, R., Cornelli, G., Frost, J., (2020). Covid-19, cash, and the future of payments, BIS Bulletin, 3, Retrieved from https:// www.bis.org/ publ/ bisbull 03.pdf.

4. Bank of England, (2020). Bank of England measures to respond to the economic shock from Covid-19, Retrieved from https:// www. bankofengland.co.uk/news/2020/march/boe-measures-to-respondto-theeconomic-shock-from-covid-19.

5. BCBS - Basel Committee on Banking Supervision, (2020). Measures to reflect the impact of Covid-19, Bank for international Settlements, Retrieved from https://www.bis.org/bcbs/publ/d498.pdf.

6. GüntherWA, Mehrizi MHR, Huysman M, Feldberg F (2017) Debating big data: a literature review on realizing value from big data. J Strateg Inf Syst 26:191-209

7. Hadad, S., Br tianu, C., (2019). Dematerialization of banking products and services in the digital era. Management \& Marketing. Challenges for the Knowledge Society, 14(3), 318-337.

8. Hess T, Matt C, Benlian A, Wiesböck F (2016) Options for formulating a digital transformation strategy. MIS Q Exec 15(2):123-139.

9. Hoe, L.K., (2020). COVID-19: opportunities and challenges for digital banks, PWCMalaysia, Retrieved from https://www.pwc.com/my/ en/ perspective/ digital/200408-pwcblog-covid-19-opportunities-challenges-digitalbanks.html.

10. IMF - International Monetary Fund, (2020). Global Financial Stability Report: Markets in the Time of COVID-19. Retrieved https:// www.imf.org/en/ Publications/GFSR/Issues/2020/04/14/global-financialstability-reportapril-2020.

11. IMF - International Monetary Fund, (2020). Policy responses to COVID-19, Romania, Retrieved from https://www.imf.org/en/Topics/imf-andcovid19/PolicyResponses-to-COVID-19\#I.

12. Tamatam, R., Dutta, P., Dutta, G. and Lessmann, S.,(2019), "Efficiency analysis of Indian banking industry over the period 2008-2017 using data envelopment analysis", Benchmarking: An International Journal, 26(8), 24172442.

13. Toor A., Hunain, M., Hussain, T., Ali, S., Shahid, A. (2016). The impact of EBanking on customer satisfaction: Evidence from banking sector of Pakistan. Journal of Business Administration Research, 5(2), 27-40.

14. Vimala, V. (2016). An evaluative study on internet banking security among selected Indian Bank customers. Amity Journal of Management Research, 1(1),63-79.

15. Zhou, L. (2004). A dimension-specific analysis of performance-only measurement of service quality and satisfaction in China's retail banking. Journal of Services Marketing, 18,534-546. 